\title{
METHODS OF ANALYSING RODENT PREY OF THE INDIAN EAGLE OWL BUBO BENGALENSIS (FRANKLIN) IN AND AROUND PONDICHERRY, INDIA
}

\author{
Mario Eric Ramanujam
}

Principal Investigator (Fauna), ECTDEF Project, Pitchandikulam Bio-Resource Centre, Auroville, Pondicherry 605101, India Address for correspondence: Research Associate, Gratitude Avian Rehabilitation, Auroville, Pondicherry 605101, India Email: tdef@auroville.org.in

\begin{abstract}
A simple key to identify the seven species of rodents which constitute the prey base of Bubo bengalensis [variously known as the Indian Eagle Owl, Bengal Eagle Owl, Great Horned Owl and Rock Horned Owl] in and around the Union Territory of Pondicherry, using only the lower mandibles, was developed for the use of raptor biologists, without going into extralimital taxonomic detail. Fundamentals of qualitative pellet analysis were found to be influenced by behaviour, and, in this regard, a methodology for an unbiased analysis had to be evolved. This was reasoned to be the sum of the number of pairs of lower mandibles in addition to the number of carcass remains with heads (thus containing lower mandibles) to give the number of rodents predated on by a pair and / or family of owls within their territory.
\end{abstract}

\section{KeYwords}

Bubo bengalensis, pellet analysis, rodents

The pellet analysis method (Errington, 1930; Uttendorfer, 1939, 1952) has become a standard practice for the identification of the prey of owls, thus replacing the gut analysis method employed by some earlier investigators (Fisher, 1893; Mason \& Lefroy, 1912). The vast majority of diurnal raptor prey studies depended upon the interpretation of carcass remains collected at the nests (Collopy, 1983; Craighead \& Craighead, 1956; Smith \& Murphy, 1973), but with a few exceptions (Kumar, 1985) this system has had little impact on owl prey spectrum studies which have relied fundamentally on pellet analysis.

A preliminary report on the prey of the Indian Eagle Owl Bubo bengalensis in and around Pondicherry exists (Ramanujam, 2001), but species specific identification of rodents was not undertaken - imperative since rodents were found to constitute $55.12 \%$ of the prey base.

\section{The objectives of this study were to:}

1. Evolve a system to ascertain the number of rodents predated on by a pair / family of owls within their territory, taking into account mandibular remains from both pellets and carcasses (quantitative analysis), and

2. Provide a simple key, relying solely on lower mandibles, to act as an identification guide to the seven species of rodents known to be predated on by Bubo bengalensis in this region (specific identification).

\section{Methods}

Area and subjects: The region extending from Ousteri Lake $\left(11^{\circ} 95^{\prime} \mathrm{N} \& 7^{\circ} 73^{\prime} \mathrm{E}\right)$ north-eastwards through Success-Ravena on the Auroville Plateau $\left(11^{\circ} 98^{\prime} \mathrm{N}, 79^{\circ} 81\right.$ 'E) to Bommayarpalayam - Kalapet on the seashore $\left(12^{\circ} 03^{\prime} \mathrm{N} \& 79^{\circ} 86^{\prime} \mathrm{E}\right)$ - all in a radius of ca. $12-15 \mathrm{~km}$ from Pondicherry City - is corrugated by a number of ravines. This broken-up country is the ideal habitat of Bubo bengalensis in this region. Field studies were centred on four breeding pairs and their young in the ravines adjoining the Sri Aurobindo Ashram Trust's wasteland development programme at Merveille and the Auroville communities of Aranya, Hermitage and Success.

Period and procedure: From March 1997 to December 2002, over 5,000 field hours were spent observing the four pairs and their young in the process of their daily lives and at their nests. This yielded much valuable data that has been particularly relevant to the present analysis, e.g., discerning territorial boundaries (Ramanujam, 2003a) and prey sharing. Pellet and carcass gathering exercises were concurrently held along with these bird-watching sessions, and the ravines and the surrounding plateaux were thoroughly scoured at every given opportunity. Over 3,000 rodents were identified as owl prey from both pellets and carcass remains. In addition, trapping, both by the research team and tribal Irulas supplemented these collections. Identification was based on all discernable taxonomic details - cranial, mandibular, dental and limb bone characteristics and measurements (Agrawal, 1967, 2000; Biswas \& Tiwari, 1969) - an exhaustive process which enabled us to arrive at a simplified key. Specific identification relied not so much on size, which is highly variable, but on the distinctive shapes and degree of development of the coronoid, condyloid, angular and masseteric processes. Identification of carcass remains followed basic morphological characteristics (Ellerman, 1947a,b; Prater, 1993).

\section{Results}

Quantitative and specific analysis of rodent prey presents a number of ambiguities due to the following reasons:

1. Contrary to popular belief (that owls ingest prey whole), prey is often torn apart using beak and claws, a la diurnal raptors, and only partly consumed. This trait has also been recorded in captives (Ramanujam, 2000). Hence it is most often not possible to put together an entire skeleton of the prey, as is supposed to be the case in popular literature. Exceptions do exist, especially concerning small prey, e.g., mice (Mus spp.) have never been known not to have been consumed whole.

2. Occasionally an owl will return to the remainder of its prey. This is not random behaviour, but shows a mnemotaxic orientation based on conditioning. In the same area, this same behaviour has been recorded in migrating Peregrine Falcons 
Falco peregrinus calidus (Ramanujam, 2003b). Hence it is quite possible that the same prey item occurs in more than one pellet regurgitated by the same bird.

3. Quite often a prey item is shared. This is particularly pertinent at the nest, where a single large rodent is used to feed many mouths. In addition, it has been observed that in many instances, a pair shares larger prey items - once the hunter has had its fill, its mate consumed the remainder. Juveniles too wait for their parents to satisfy themselves before appropriating the remainders. Therefore, the remains of the same prey item are bound to occur in two or more pellets of different birds.

4. The digestive 'juices' and alimentary contractions of owls seem so strong so as to pulverize bones. This is particularly relevant to the craniums, which in the majority of cases get fragmented beyond recognition - unfortunate since most biologists depend upon them for taxonomical purposes. Teeth are either too easily displaced from their sockets and may get lost if carelessly handled during analysis, or, being brittle, get damaged or damage root holes when extracted. Bones also get damaged if exposed to the elements for too long. In addition, major variations in size are known to occur among rodents (Roonwal \& Agrawal, 1966; Roonwal \& Roy, 1968). All these preclude consistently using cranial and dental measurements, or counting roots and root holes for specific identification. The only bones that remain relatively undamaged are the lower mandibles, and a pair of these could be assumed to constitute a single prey item. This fact has long been recognised by the Hawk and Owl Trust (Anon., 1995), but has yet to be condoned by purists who also depend upon craniums and limb bones for specific identification (rightly so when closely related taxa are under scrutiny).

All the above mentioned empirical factors could create a bias if not taken into account during analysis. It must be realized that a random collection of pellets cannot answer quantitative analysis -- as often happens, any random bone or bones in a pellet alone cannot be said to constitute a single prey item (as other bones from the same prey item may be present in other pellets), nor group of bones a said number of prey items -- so on and so forth. Also, pellets alone cannot be used in analysis; carcass remains too have to be taken into account. Also, it is imperative while planning a methodology for the collection and analysis of prey, to take into account the territorial range occupied by a pair of owls and the number of young with them at a given period of time (young have been known to remain with their parents for up to 9 months). All pellets, pellet remains and carcasses collected within demarcated territorial boundaries must be analysed in relation with each other and only this can give a fair unbiased estimate of the prey requirements of a pair and / or family of owls. Therefore, it stands to reason that the number of pairs of lower mandibles plus carcass remains with heads attached (thus containing the lower mandibles) equal the quantity of individual rodents predated on by a pair and / or family of owls.

For specific identification of rodents predated on by Bubo

bengalensis refer Fig. 1.

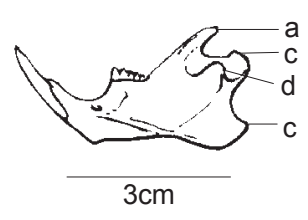

Large Bandicoot Rat Bandicota indica Robust form and large size distinguishes this. All processes are prominently developed.

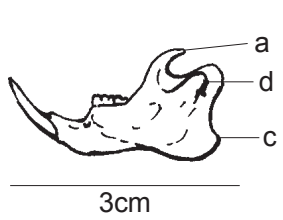

Lesser Bandicoot or Mole Rat Bandicota bengalensis

A slightlymore curved coronoid process, and marginally less pronounced angular process distinguish this from the previous. The masseteric process is prominently developed.

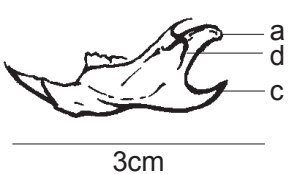

Indian Gerbil Tatera indica

The elongated shape, very fine coronoid process and well developed upcurved angular process distinguish this. The masseteric process is prominently developed.

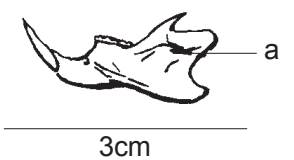

Common House Rat Rattus rattus

The masseteric process is poorly developed, whereas the other processes are prominently developed.

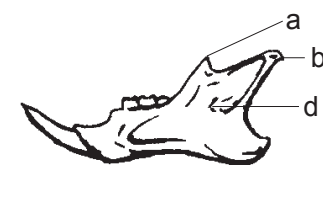

$3 \mathrm{~cm}$

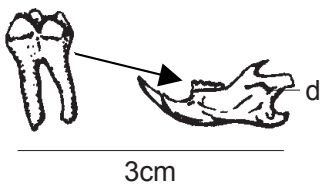

Three-striped Palm Squirrel Funambulus palmarum

The linear angles of the poorly developed coronoid process and long condyloid process, in addition to the rudimentary masseteric process are distinctive.

Mice Mus spp. (House mouse Mus musculus and Little Indian Field Mouse Mus booduga)

In spite of valuable work regarding forms belonging to the genus in the Indo-Malayan region (Marshall, 1977, 1986), many anomalies

exist and taxonomical details still remain unresolved (Agrawal, 2000; Srinivasulu \& Pradhan, 2003). As such, specific identification is not practicable at this stage. Suffice is to say - in this context - mouse cheek teeth have rounded tops with shiny white enamel (enlarged in inset) unlike any of the previous (whose cheek teeth are ridged transversely) and the masseteric process is intermediate in development. Mandibular length ranges widely from that shown to $<5 \mathrm{~mm}$ depending on age and size of animal predated on.

Figure 1. $a$ - Coronoid process; $b$ - Condyloid process; $c$ - Angular process; $d$ - Masseteric process 


\section{Discussion}

That neglecting ethological principles when interpreting ecological data can seriously bias results became obvious in the course of this ongoing study concerning the prey of Bubo bengalensis. Seemingly extralimital behaviour - e.g., prey sharing, and territory and number of individuals occupying it do not at first seem to have a direct bearing on food spectrum studies, but, as explained earlier, these play significant roles in both qualitative and quantitative analyses.

Simplified identification guides targeted towards the general field biologist and lay-man exist in some countries, and even in popular literature, for e.g., the Hawk and Owl Trust's "Great Barn Owl Pellet Exchange" programme in the United Kingdom (Anon., 1995). Unfortunately, we lack such interactive approaches in our country. In this sense, this report is only to be treated as the beginning of such an exercise. Further data, concerning rodent identification in other regions, would be invaluable and greatly facilitate research into raptor biology.

\section{REFERENCES}

Agrawal, V.C. (1967). Taxonomic study of the skulls of Oriental rodents in relation to ecology. Records of the Indian Museum 60: 125-326

Agrawal V.C. (2000). Taxonomic studies of Indian Muridae and Hystricidae (Mammalia: Rodentia). Records of the Zoological Survey of India, Miscellaneous Publication, Occasional Paper No. 180, 177pp. Anon. (1995). The Great Barn Owl Pellet Exchange - What was for dinner? A guide to the contents of an owl pellet. B.B.C. Wildlife 13 (1): 18-19

Biswas, B. and K.K. Tiwari (1969). Taxonomy and distribution of Indian Rodents. Proceedings of the Indian Rodent Symposium, Calcutta 1969, 9-45.

Collopy, M.W. (1983). A comparison of direct observation and collection of prey remains in determining the diet of Golden Eagles. Journal of Wildlife Management 47(2): 360-368.

Craighead, J.J. and F.C. Craighead (1956). Hawks, Owls and Wildlife. Stackpole Co., Harrisburg, Pennsylvania, and Wildlife Management Institution, Washington D.C. Dover Publications Reprints, N.Y., 443pp. Ellerman, J.R. (1947a). A key to the Rodentia inhabiting India, Ceylon and Burma based on the collections in the British Museum. Part I. Journal of Mammalogy 28: 249-278.

Ellerman, J.R. (1947b). A key to the Rodentia inhabiting India, Ceylon and Burma based on the collections in the British Museum. Part 2. Journal of Mammalogy 28: 357-387.

Errington, P.L. (1930). The pellet analysis method of raptor food habits study. Condor 32: 292-96.

Fisher, A.K. (1893). The hawks and owls of United States in their relation to agriculture. U.S. Deparment of Agriculture (Division of Ornithology and Mammals) Bulletin 3: 1-210.

Kumar, T.S. (1985). The Life History of the Spotted Owlet (Athene brama brama Temminck) in Andhra Pradesh. Monograph of the Raptor Research Centre, Hyderabad. 241pp.

Marshall, J.T. Jr. (1977). A synopsis of Asian species of Mus (Rodentia, Muridae). Bulletin of the American Museum of Natural History 158: 173-220.

Marshall, J.T. Jr. (1986). Systematics of the Genus Mus. The Wild Mouse in Immunology: Current Topics in Microbiology and Immunology. 127: $12-18$.

Mason, C.W. and H.M. Lefroy (1912). The food of birds in India. Memoirs of the Department of Agriculture in India, Entomology Series 3: 376pp.

Prater, S.H. (1993). The Book of Indian Animals. Fourth impression (First published 1948). Bombay Natural History Society and Oxford University Press, 324pp.
Ramanujam, M.E. (2000). Food consumption and pellet regurgitation rates in a captive Indian Eagle Owl (Bubo bubo bengalensis). Zoos' Print Journal 15(7): 289-91.

Ramanujam, M.E. (2001). A preliminary report on the prey of the Eurasian Eagle Owl (Bubo bubo) in and around Pondicherry. Zoos' Print Journal 16(5): 487-88.

Ramanujam, M.E. (2003a). On the "Long Call" of the Indian Great Horned or Eagle Owl Bubo bengalensis (Franklin). Zoos' Print Journal 18(7): 1131-34.

Ramanujam, M.E. (2003b). New Bird on the Block. Newsletter for Birdwatchers 43(2): 22.

Roonwal, M.L. and V.C. Agrawal (1966). Measurements of rodents (Mammalia), especially their skull for taxonomic purposes. Records of the Indian Museum, Delhi 60: 81-93.

Roonwal, M.L. and S.G. Roy (1968). Variability in size of body parts and skull in the Manipur Rat Rattus rattus bullocki. Journal of the Zoological Society of India 18: 46-48.

Smith, D.G. and J.R. Murphy (1973). Late summer food habits of burrowing owls in central Utah. Raptor Research 7: 112-115.

Srinivasulu, C. and M.S. Pradhan (2003). Checklist of Murids (Mammalia: Rodentia: Muridae) of South Asia. Zoos' Print Journal 18(12): 1286-1310.

Uttendorfer, O. (1939). Die Ernahrung der Deutschen Raubvogel and Eulen. Neudamn, Neumann.

Uttendorfer, O. (1952). Neue Ergebnisse uber die Ernahrung der Greifvogel and Eulen. Eugen Ulmer, Stuttgart.

\section{ACKNOWLedgements}

I sincerely wish to thank the European Commission's Tropical Dry Evergreen Forest (EC-TDEF) Project and Pitchandikulam Bio - Resource Centre for facilitating this and other studies on the fauna of this region

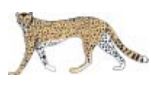

\section{EDITORIAL ASSISTANT required at Zoo Outreach Organisation}

\section{Publication: Zoos' Print Journal}

Job Location: Coimbatore

Essential Qualities: Postgraduate or graduate in Wildlife / Zoology / Botany or Life Sciences. Proficiency in spoken, written and technical English. Computer savvy with some knowledge of DTP, clear understanding of or interest in conservation / wildlife. Open to flexible work hours and hard work.

Responsibilities: Editing, coordinating, corresponding with authors/reviewers, proof reading, typesetting, and web-based publishing.

Salary will be in keeping with qualification and experience. Applicants should send: Cover letter, résumé and names+addresses of three professional references, either by mail, fax or email to:

Sanjay Molur, Editor, Zoos' Print Journal

Zoo Outreach Organisation, 29-1 Bharathi Colony, PB

1683, Peelamedu, Coimbatore, Tamil Nadu 641004

Ph: +91 422 2568906, 2561743, 2561087

Fax: +91 4222562369

Email: herpinvert@vsnl.com; zoocrew@vsnl.net 